\title{
How COVID-19 induced panic on stock price and green finance markets: global economic recovery nexus from volatility dynamics
}

\author{
Luc Phan $\operatorname{Tan}^{1} \cdot$ Muhammad Sadiq $^{2} \cdot$ Talla M. Aldeehani $^{3} \cdot$ Syed Ehsanullah ${ }^{4} \cdot$ Putri Mutira $^{5} \cdot$ Hieu Minh Vu ${ }^{6}$
}

Received: 8 October 2021 / Accepted: 23 November 2021 / Published online: 1 December 2021

(c) The Author(s), under exclusive licence to Springer-Verlag GmbH Germany, part of Springer Nature 2021

\begin{abstract}
This paper investigates the effect of different categories of essential COVID-19 data from 2020 to 2021 towards stock price dynamics and options markets. It applied the hypothetical method in which investors develop depression based on the understanding suggested by various green finance divisions. Furthermore, additional elements like panic, sentiment, and social networking sites may impact the attitude, size, and direction of green finance, subsequently impacting the security prices. We created new emotion proxies based on five groups of information, namely COVID-19, marketplace, lockdown, banking sector, and government relief using Google search data. The results show that (1) if the proportional number of traders' conduct exceeds the stock market, the effect of sentimentality indexes on jump volatility is expected to change; (2) the volatility index component jump radically increases with the COVID-19 index, city and market lockdown index, and banking index; and (3) expanding the COVID-19 index gives rise to the stock market index. Moreover, all indexes decreased in jump volatility but only after 5 days. These findings comply with the hypotheses proposed by our model.
\end{abstract}

Keywords COVID-19 $\cdot$ Market lockdown $\cdot$ Government relief $\cdot$ Green finance $\cdot$ Stock price $\cdot$ Responsible Editor: Nicholas Apergis

\section{Introduction}

Since it first emerged in December 2019, the coronavirus (i.e., COVID-19) has been impacting the global financial markets particularly the United States of America (USA) where it induces the country's stock market drops and violaceous increases in share market, subsequently contributing to massive financial market upheaval. As of 18 April 2021,

Responsible Editor: Nicholas Apergis

Hieu Minh Vu

hieu.vm@vlu.edu.vn

Luc Phan Tan

lucpt@tdmu.edu.vn

Muhammad Sadiq

muhammad.sadiq@taylors.edu.my

Talla M. Aldeehani

talla@cba.edu.kw

Syed Ehsanullah

syed_ehsan_ullah@oyagsb.uum.edu.my

Putri Mutira

putri.mutira@gmail.com the COVID-19 pandemic has killed 574,957 people in the USA that is 12 times higher than the death toll of regular flu virus (Basu 2020). Such situation imposes a major threat mainly to the general public's health and thus prompted the White House to impose social separation at all levels of society on 16 March 2020 as part of the national initiatives to curb the spread of COVID-19. Following such move, many businesses have been permanently closed or sought bankruptcy protection. This results in an alarming pique of

1 Thu Dau Mot University, Binh Duong, Vietnam

2 Faculty of Business and Law, School of Accounting and Finance, Taylor's University Malaysia, Subang Jaya, Malaysia

3 College of Business Administration, Kuwait University, Kuwait City, Kuwait

4 School of Accountancy, Universiti Utara Malaysia, Changlun, Malaysia

5 Universitas Pembangunan Jaya, South Tangerang, Indonesia

6 Faculty of Business Administration, Van Lang University, 69/68 Dang Thuy Tram Street, Ward 13, Binh Thanh District, Ho Chi Minh City, Vietnam 
investors' interest and triggers massive volatility in the US equity and options markets.

Market fear is commonly shown in the financial market through market volatility assessments. It is often known by market players as a fear index that is measured via the VIX index and the Chicago Board Options Exchange. These measures were designed with the S\&P Index Options price for out-of-the-money options through the COVID19 pandemic where the S\&P 500 dives (VIX index) spiked promptly after three significant events. The first event occurred on 21 February 2020, when the number of COVID-19 cases in Germany was declared a pandemic outbreak period. Meanwhile, the second event happened on 11 March 2020 when the former US President, Donald Trump, announced COVID-19 as a global pandemic and restricted travelers from Europe. Finally, the third event occurred on 13 March 2020 where the US President confirmed a state emergency. On Sunday, 16 March 2020, the volatility index achieved its all-time high. In addition to the market attention, COVID-19 has also caused massive turbulence in stock price levels as well as market volatility and movement.

The main objective of this paper is to look at the effect of COVID-19 on the diverse groups of important information pertaining to the price dynamics of stock and stock options markets from January 1, 2020 to January 1, 2021. As previously stated, the stock and options markets were highly volatile from 25 February 2020 to 15 April 2020. This paper thoroughly investigates the price impact for dynamics on the stock market, the options market, and the significant disparities in various types of COVID-19 information. We argue that the new information process impacting security price is more complex than the value of incremental information that is directly mapped. Especially in extreme stress, we propose that different information categories receive various levels of attention from traders, subsequently generating variable response intensities. This can be seen in the case of two new pieces of COVID-19 financial information, namely "100,000 deaths" and "New York implements a lockdown". In both circumstances, the influence of green finance items is a complex process of turning into the proper payment pertinence of particular securities or bond indexes. The extent to which a trader pays attention to green finance and the intensity with which they react are significant factors in these pieces of information.

This paper utilized the equilibrium model of 2 types of merchant green money economy based on data shocks. A decade after the global recession, the world continues to grapple with issues that emerged from the 2007-2009 event. Several studies suggest that there is now a need to create a healthy environment characterized by carbon-free and ecologically friendly techniques that can be achieved through green finance. In order to build a sustainable future, stakeholders and policymakers may benefit from supporting green bonds, green loans, and green mortgages (Štreimikienė and Kaftan 2021). The lead dealers commit discerning errors foreseeing future projected costs and such missteps are conveyed with a mean equivalent to the strength of feeling. However, equilibrium prices and its dynamism depend on the error and security of behavioral traders where expert traders who live along the same economy are not subject to perceptive errors. Therefore, the model in this paper aims to prove the part of spirits in different green finance categories. We expect that the relative extent of direct merchants in the securities exchange is more significant than in the choices market. Based on these presumptions, the supposition power for five specific information for stock and alternatives market instability elements is believed to have numerous impacts.

This paper provides four main contributions to the topic under investigation. First, it focuses on understanding how various types of information influence dynamics prices time of a high-stress period. Second, the strength of our feeling can be crucial for the price move beyond the magnitude and the orientation of various green finance events. Third, different sentimental indexes will influence the jump discontinuity level in stock and options market volatility measurements. Finally, the fourth contribution is pertinent to the current pandemic situation in relation to the prominent role of trade with behavioral tasks choosing the best market, where (i) we influence the dynamic of equilibrium price on the stock and options markets that emerge from the activities of both behavioral traders and brilliant traders, and (ii) we create forecasts of diverse green finance category sentiment rates to jump the components of stock markets and selection volatility movements. This paper also applied a new empirical strategy by directly dealing with feeling indexes rather than using the measures of green finance intensity. Such strategy highlights on the sophistication of feeling indexes for distinct green finance genres.

Furthermore, this paper utilized Google's COVID-19 data to determine the time intensity of the different green finance categories. It involved the application of five green finance categories with the highest effect, namely (1) COVID-19 green finance, (2) market green finance, (3) lockdown green finance, (4) banking green finance, and (5) government aid. We are aware that each green finance category will positively or negatively affect the economic aspects that map security price movements. The intricacy of such mapping is the types of green finance where supplementary factors such as emotion and political sympathy contribute to the strength of green financing and its impact towards security prices.

This paper is arranged according to several sections. The "Literature review" section contains a review of literature related to the green finance shocks in stock and how the present paper relates to recent studies on COVID-19 and financial market implications. Meanwhile, the "Green finance model" section explains the exogenous advanced green 
finance model and COVID-19 shock from the perspective of a theoretical economic model. This is followed by the "Data on COVID-19 pandemic" section that contains the phrasing of our theory and presents important information related to COVID-19 and the stock market. Finally, the "Results and discussion" section reports the empirical results of the investigation while the "Conclusion and policy implication" section contains the concluding remarks.

\section{Literature review}

In this study, balanced price was derived from the green finance of both conduct and advanced traders. Conduct traders often make perceptual errors when it comes to future expenses and therefore tend to pick the best stocks. In addition to green finance, this study also placed close attention to the feelings caused by various green finance genres. Our theoretical projections are based on the greater significance of the stock market (stock and behavioral traders). Past literature stated that sentiment is important in the price dynamics where behavioral traders are more projects in the before and after country stock markets.

Based on the predicted asset pricing models from February to July 2020 , it is suggested that high stock volatility in the COVID-19 period was induced by the fluctuations in feeling or risk aversion (Arif et al. 2021). In addition, the stock market and index volatility were explained in July 2020 instead of the government relief operations. We believe that such condition was influenced by country markets with volatility measurements in the stock market and other options markets. Therefore, direct sentiment indicators from five green finance categories were employed in this study.

Furthermore, the hedging needs for sophisticated investors drive the use of index options. According to Lemmon and $\mathrm{Ni}$ (2014), individual stock options and underlying stock green finance are driven by the hedging demand of individual investors, which is heavily impacted by the market mood. This study thus hypothesizes that behavioral traders make more money from the stock market than from other market options. As previous literature suggests various sentiment assessments (Beraha and Đuričin 2020), we therefore advanced trust on the sentimentality-based index that is more significant in two features. First, we created a proxy based on a specific category such as green finance attention and responsiveness. Second, the green finance based on Google search traffic varied with our feelings daily. Google's daily search volume has been employed in a number of previous studies to create a measure of investor sentiment where it allows more time to capture investor awareness (Da et al. 2011). In this regard, investors' emotion assessment based on Google data search volume is superior than the predictability of others. Although numerous studies have looked on the impact of sentiment towards the bond market, there has been relatively scarce research on its impact towards the global economy (Piñeiro-Chousa et al. 2021).

\section{COVID-19: recent research}

The COVID-19 pandemic along with the lockdowns and social distancing practices executed by governments to curb its global outbreak has imposed profound influence on the worldwide financial markets, including the USA. It was reported that COVID-19 has a more significant impact on the US stock market than other past pandemics such as the Spanish flu (Baker et al. 2020). Moreover, several studies showed that the COVID-19 outbreak has imposed adverse impact towards security markets ( $\mathrm{Li}$ et al. 2021; Ferreira et al. 2020; Yang and Chuang 2020; Yoshino et al. 2021). Therefore, this paper develops sentiment proxies for various green finance categories that include COVID-19, Market, Lockdown, and Banking. It also looked at the price fluctuations of five distinct sentiment indicators in the stock market as well as other markets.

Several studies have propounded on the substantial effect of the pandemic towards bonds. According to Chien et al. (2021), unexpected variations in COVID-19 infection trajectories are capable to predict the US inventory returns. Moreover, the early outbreak of the pandemic revealed enterprises in labor-intensive industries and localities with significant mobility losses (Bretscher et al. 2020). A number of studies also examined the shortfall in the early phase of the pandemic from the US financial market perspective. Cheng (2020) reported that the VIX future prices had fall below the VIX index of March 2020. In this regard, the lack of response on optional implied actions prompted the decreasing reaction to the implied optional density towards the COVID-19 pandemic (Hanke et al. 2020; Jackwerth 2020). In addition, the US stocks also indicated skewness and CDS spread in less resilient pandemic sectors has expanded over the market index (Sadiq et al. 2021a). As for banking, studies on bank demands for liquidity have found that the highest increase in liquidity requirement was recorded during the early emergence of COVID-19 (Li et al. 2020). It was also discovered that stock prices were lower than those banks exposed to substantial ex-ante loan lines and significant ex-post massive gross had plummet (Chien et al. 2021).

On the other hand, several evidences posit that the COVID-19 outbreak increases the number of contagion pathways in international financial system (Guo et al. 2021). This is further supported by the availability of various global stock market interconnections before and after the epidemic (Zhang et al. 2020) and that internationally focused companies were underperforming during the onset of the epidemic (Chuan et al. 2021) 


\section{Green finance model}

During times of high capital stress, pieces of the green finance model often map various sensations based on financial and non-economic causes. Behavioral traders are designed to create perceptual errors that correspond to market reactions towards various forms of green finance. In this regard, the stock market is more active for behavioral traders, whereas the options market is more visible for experienced traders. We plotted the price and impact of five distinct forms of green financing and emotion intensity on the volatility dynamics of the stock and options market. The sentiment metrics derived from Google search results were used to support our empirical findings. Intelligent investors with balanced opportunities and conduct traders are the two categories of agents in this model along with the measurement of conduct traders and the inclusion of sophisticated traders. In order to optimize their projected usefulness, both agents chose their portfolios depending on their present views on the ex-ante average price distribution, where $p t$ refers to the current price. Furthermore, two assets pay equal dividends in the economy and safe asset is one of the possessions that receives a fixed total payment.

In contrast, hazardous investment always pays the same set of absolute dividend. We also assumed that risky asset is delivered exogenously. This is because various types of green finance shocks can influence the state of the economy and the price of safety at various stages of the COVID-19 pandemic. As a result, various green finance categories will generate varying market sentiments throughout the year. We also assumed that the interval is distributed uniformly. It is due to the fact that the magnitude and direction of green finance are not solely contingent. This reflects the amount of attention reflected by the market participants and how they react to information, which can be important for non-economic factors like fear and emotion. Furthermore, the actual value could be extremely high or low as well as good or bad (Sadiq et al. 2021b). The variable volatility index dynamics on both stock market and options market also play a significant part in our approach. Therefore, the representative merchants of conduct often produce perception errors depending on the extent of their achievement. The conduct traders misinterpret the projected price of a risky property during the term. It is also assumed that the mean and variance are typically distributed, where such assumption indicates that it is considered higher if its value is positive. The nature of the link between behavioral traders and sentiment dealers make them different. In this regard, positive shock across the economy is likely to prompt the traders in making positive mistakes and vice versa. Furthermore, positive surprise will advance the price towards a good deal. Since the sign is also positive, we can characterize the behavioral traders' misperceptions as an overreaction to the exogenous shock. While experienced traders can assimilate the green finance accurately, behavioral traders can do so only with a mistake. A constant absolute risk-averse function of wealth is the utility of every agent at the time:

$U=-e^{-(2 \gamma) w}$

where $\gamma$ is the absolute aversion risk coefficient. Furthermore, regularly distributed returns for holding a unit of risky assets will cultivate the maximum predicted value (1) to correspond with the maximum.

$\bar{\omega}-\gamma \sigma_{\omega}^{2}$

where $\bar{\omega}$ represents the stock asset final and $\sigma_{\omega}^{2}$ shows the asset with 1 passé modification of the asset. The intelligent dealers and conduct traders also select their holdings and the hazardous asset to maximize their predicted usefulness. In order to optimize its dangerous asset, the savvy investors chose to:

$E\left(U^{s}\right)=c_{0}+\lambda_{t}^{b}\left[d+p_{t+1}-(1+r) p_{t}\right]-\gamma\left(\lambda_{t}^{b}\right)^{2}\left(\sigma_{p_{t+1}}^{2}\right)$

$=\pi r^{2}$ where $c_{0}$ is a first-period labor revenue function and $\sigma_{p_{t+1}}^{2}$ is a one-period variance of $p_{t+1}$. Similarly, the behavioral traders elected to maximize their possession of hazardous assets.

$E\left(U^{b}\right)=c_{0}+\lambda_{t}^{b}\left[d+p_{t+1}-(1+r) p_{t}\right]-\gamma\left(\lambda_{t}^{b}\right)^{2}\left(\sigma_{p_{t+1}}^{2}\right)+\lambda_{t}^{b}\left(\varepsilon_{t}\right)$

The smart traders' maximum holding can be shown as:

$\lambda_{t}^{s}=\frac{d+p_{t+1}-(1+r) p_{t}}{2 \gamma\left(\sigma_{p_{t+1}}^{2}\right)}$

Through the same way, the behavioral traders may demonstrate the maximum holding:

$\lambda_{t}^{b}=\frac{d+p_{t+1}-(1+r) p_{t}}{2 \gamma\left(\sigma_{p_{t+1}}^{2}\right)}+\frac{\varepsilon_{t}}{2 \gamma\left(\sigma_{p_{t+1}}^{2}\right)}$

Because anticipated prices are inaccurate, the empirical model in this paper illustrates that the behavioral traders should store a rare type of risk, which primarily depends on the high sentimentality level of those outcomes for the exogenous green finance shock. This signifies that conduct traders believe the expected price will be as low as possible. We may now investigate the effects on the current balance price of behavioral traders. In the absence of the conduct traders, the price will be equally satisfied where the 
provision of the risky asset is located. In this situation, the price of balance is:

$p_{t}^{s}=\frac{d+p_{t+1}-2 \gamma\left(\sigma_{p_{t+1}}^{2}\right) \Psi}{1+r}$

The market balance price can be determined in the presence of behavioral traders:

$(1-P) \lambda_{t}^{s}+\theta \lambda_{t}^{b}=\Psi$

$\frac{d+p_{t+1}-(1+r) p_{t}}{2 \gamma\left(\sigma_{p_{t+1}}^{2}\right)}+\theta \frac{\varepsilon_{t}}{2 \gamma\left(\sigma_{p_{t+1}}^{2}\right)}=\Psi$

$p_{t}^{s b}=\frac{d+p_{t+1}-2 \gamma\left(\sigma_{p_{t+1}}^{2}\right) \Psi}{(1+r)}+\frac{\theta \varepsilon_{t}}{(1+r)}$

When we compare Eq. (7) and on average Eq. (10), it can be seen that $p_{t}^{s b}$ is above $p_{t}^{s}$ when $k_{t}$ is positive. Again, when the equations are compared, the average $p_{t}^{s b}$ size is lower when $k_{t}$ is negative. It indicates that the behavioral traders' over-responses have caused a disorder in the overall surplus demand, which makes the current balancing prices overreact to feel shocks. The volatility resulting from this can be determined as follows:

$$
\begin{aligned}
A & =\pi r^{2} \\
\sigma_{p_{t+1}}^{2} & =\frac{d+p_{t+1}-(1+r) p_{t}}{2 \gamma \Psi}+\frac{\theta \varepsilon_{t}}{2 \gamma \Psi}
\end{aligned}
$$

Similarly, Eqs. (10) and (11) specify the type of feeling shocks, the behavioral traders' perceptive errors and level of involvement in the relevant markets, equilibrium prices at the time, and price dynamics through the green finance volatility. Our empirical forecasts relate to the stock market volatility dynamics and options market based on the green finance parameters.

\section{Hypothesis formulation}

This section presents the 3 hypotheses related to the dynamic price level of the stock market and the country market for showjumping options. Each hypothesis is linked to a distinct COVID-19 green finance shock. Empirical proxies of the essential components and our empirical examination of these assumptions will utilize our description and provide details of volatility. We consider the following phases in our model to determine how green finance shocks affect prices. First, there are updates on several types of COVID-19. Various green finance may provide incremental information at different levels. Economic agents pay varied amount of attention to green finance and react in multiple ways depending on its economic value. Moreover, fear, emotion, and enthusiasm are examples of noneconomic forces. The networks' social media reactions also have an impact on them. This procedure cultivates the level of feeling caused by the green finance shock. We simulate how perceptive errors made by behavioral traders are directly affected because it is distributed normally with a mean and variance. Data on COVID-19 obtained from Google searches throughout the period of 21 January 2020 to 8 June 2020 was used to build empirical metrics at sentiment levels that reflect a range of COVID-19-related information shocks. Different forms of new information relating to COVID-19 may lead to changes in sentiment. This comprised information related to health, information on the impact of the COVID-19 outbreak on the economy, banks, and economic markets, and information pertaining to the legislative efficiency of government rescue measures. New data on the extent to which the economy is shut down was also available. Such COVID-19 data would impact the security prices and whether it was circuitously or unswervingly related to economic considerations in the stock and options market. As noted in the previous paragraph, we decided to represent different types of green finance leading to various feelings, thus altering the stock and option prices. Instead of focusing on the content measurements of green finance and its direction, we directly worked on five categories of green finance indices and five sensation indices.

One of the accomplishments achieved by this paper is building a Google-based proxy to search information on the five different categories of green finance shock. It is worth to highlight that behavioral traders' perception errors are strongly connected to the feeling intensity towards the distinct categories of COVID-19 data. Furthermore, the presence of conduct traders could alter the pricing dynamics of the stock and options market. The green finance response by behavioral traders is delayed in specific categories of lowvalue green finance shocks. This empirical method entails on the five sentiment indices created in relation to the COVID19 green finance categories, namely (1) COVID-19 pandemic index, which is based on the dictionaries of medical and health-related terms with significant impact on security expenses, (2) search item dictionary-based index, which typically includes negative security price green finance and reactions to the market especially during March 2020, (3) search dictionary-based lockdown index, (4) banking index, and (5) governmental-aid index for the five-word diagrams utilized. The various types of green finance shock will produce a comparable sensation shock, resulting in prominent misunderstanding among the behavioral traders. Nevertheless, it should be noted that behavioral traders often have a greater stock market involvement rate.

Moreover, advanced traders are commonly elaborated in the options market. This paper believes that expert traders 
can better map the importance of various types of green finance and related indexes to security prices. The impact of our five sentiment indicators on non-continuous leaps in (1) the VIX index (S\&P 500) measurement from the index option market prices hypothesizes the impact on the $S \& D$ 500 index (2) and the S\&P 500 index, (3) along with the volatility index data of the S\&P 500 index on the price variation of equilibrium in Eqs. (10) and (11). When testing the hypothesis of intermittent hedges in the numerous volatility indices, we examined both the level of behavioral traders' participation and the form of sentimental shocks. The first three types of feeling shock substantially impacted the dynamics prices, leading to increased spring volatility. Monetary policies also could potentially impact market prices as shown in the banking green finance while government relief actions were undertaken in the legislative term. However, it might not immediately affect the jump volatility. Successful government initiatives and help programs may mitigate the adverse effects of COVID-19 green finance and lockdowns. This can lower any jumping in the VIX index by a higher degree of sentiment regarding government-assisted measures.

\section{Hypothesis 1}

The COVID-19 virus index, lockdown index, and stock market index will continue to rise due to the VIX index leap component. Meanwhile, the government relief effort index reduces the VIX index leap element. We also examined how the stock market's pricing dynamics were affected by feeling shocks amidst the COVID-19 pandemic, which is aligned with the five different green finance categories. Furthermore, price cutters, including private traders, were increasingly participating in the stock market dynamics. Incorporating the reward implications of distinct green finance categories is not precise as compared to the sophisticated traders. They can only discover with delay on the price consequences of particular green finance types in some circumstances. Behavioral traders also acknowledge the value of the (1) COVID-19 index, (2) stock market index, and (3) government aid. As previously stated, the two principal types of green finance are dominated by negative green finance and lead to stock market volatility. On the other hand, government-assisted initiatives provide a compensatory component that dampens volatility surges in the stock market. Behavioral traders are different from skilled traders in responding to sentimental clues related to the banking green finance or green lockout finance. They also have a more muted sensitivity to these variables than cultured traders. Occasionally, behavioral traders underreact or overreact for several days before calibrating a balanced reaction. We thus assume that an adequate and substantial response may take place by a postponement.

\section{Hypothesis 2}

Both COVID-19 and stock market indexes will progress the S\&P 500 index as well as the bank index jumping. The S\&P 500 index and S\&P 500 banks index both include a large COVID-19 relief component that in return, reduces the size of these indexes. In addition, the banking and lockdown indicators are complex and possess a minimal contemporary impact on the S\&P 500 index and S\&P 500 banks index jump components.

\section{Hypothesis 3}

Apart from the forecast in Hypothesis 2, we further estimate a considerable negative jump contribution for the realized volatility component of S\&P 500 and the S\&P 500 banks index if the index and the lockdown index are delayed by a specific number of days.

\section{Data on COVID-19 pandemic}

This section discusses about the summary of data related to the COVID-19 pandemic, which comprises data on the rate of COVID-19 deaths obtained from various state authorities. Whereas the Yahoo.com webpage provided daily data on the level of S\&P 500 index, the Chicago Board Options Exchange (CBOE) website contained VIX-related information, while the Department of Defense website provided data on significant occurrences. Panel A in Table 1 contains COVID-19 data retrieved between January 2020 and June 2020. It comprises a statistical summary of the COVID-19 pandemic including the S\&P 500 index, S\&P 500 banks index, and the Chicago Board Options Exchange (VIX) data from 21 January 2020 to 8 June 2020. Meanwhile, panel B presents COVID-19 data from 20 January 2020 to 31 January 2020 from the context of the USA, S\&P 500 index, and the Chicago Board Options Exchange (VIX) index. Additional data was also obtained from state authorities pertaining to the number of COVID-19 cases, deaths, and recoveries. The daily COVID-9 growth rate and the symmetrical daily growth rate were also included in the sample for the period of 2 March 2020 to 8 July 2020. All statistical data in both panels are presented via descriptive statistics and percentages.

As shown in Table 1, the number of cumulatively confirmed COVID-19 cases had increased from 1 case on 21 January 2020 to $1,934,828$ cases on 8 June 2020 and $24,384,746$ cases on 31 December 2021. With a population of 328.2 million people in 2019 , approximately $0.59 \%$ of the US population had contracted the pandemic and it surged to $7.43 \%$ by the end of January 2020. A number of studies reported that more than $50 \%$ 


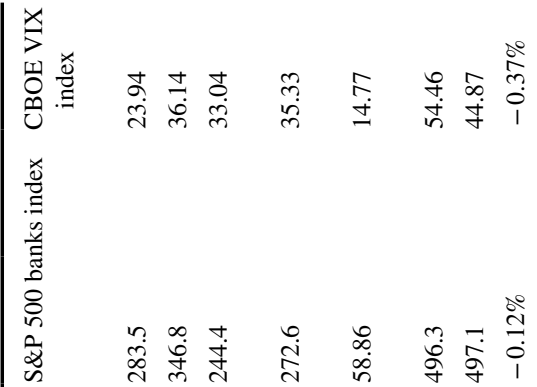

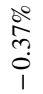

\begin{tabular}{cc}
8 & 7 \\
$\infty$ & \multirow{2}{*}{} \\
$\infty$ & 1
\end{tabular}

g̊

:

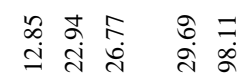

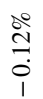
$\stackrel{\substack{0 \\ \infty}}{\stackrel{\infty}{a}}$

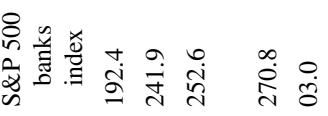

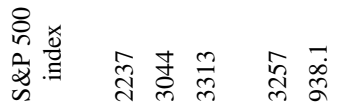

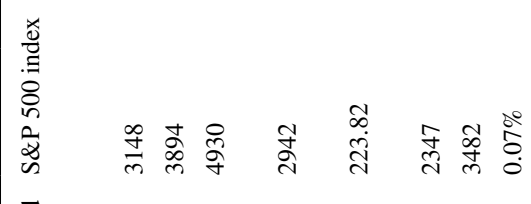

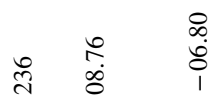

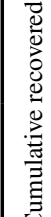

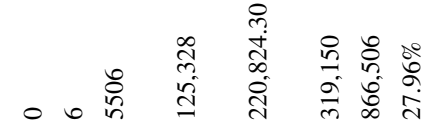

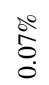

$\frac{3}{2}$

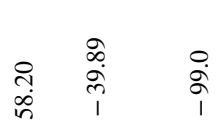

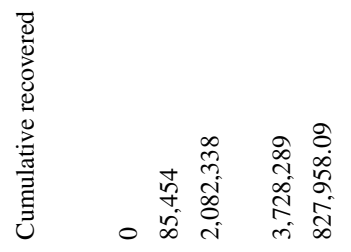

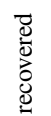

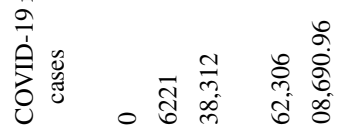

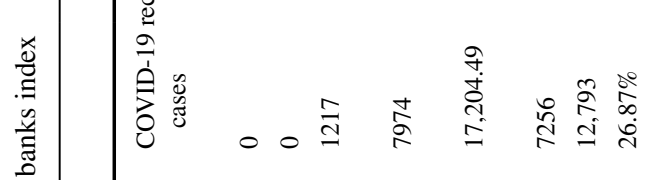

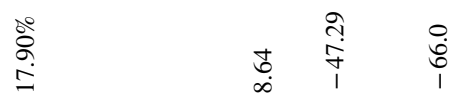

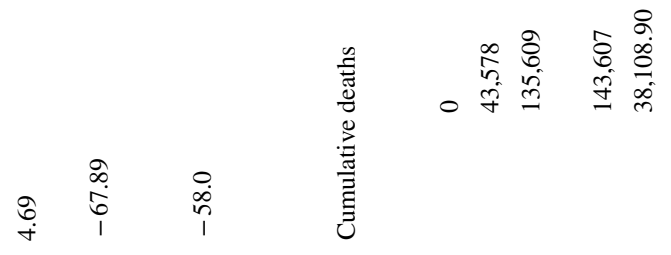

$\stackrel{\stackrel{\circ}{2}}{\frac{2}{2}}$

तิ

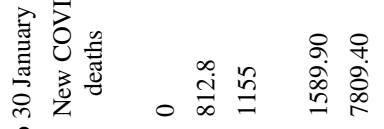

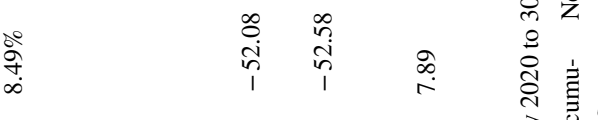

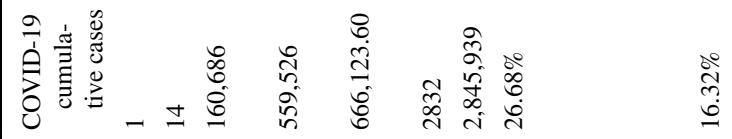

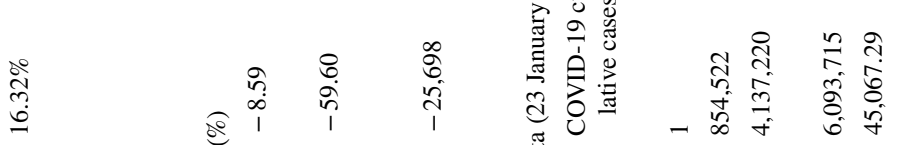

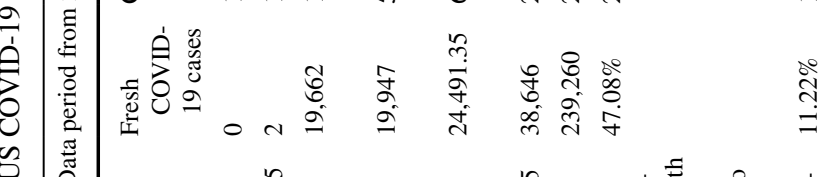

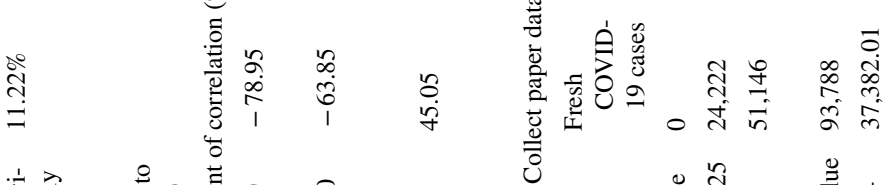




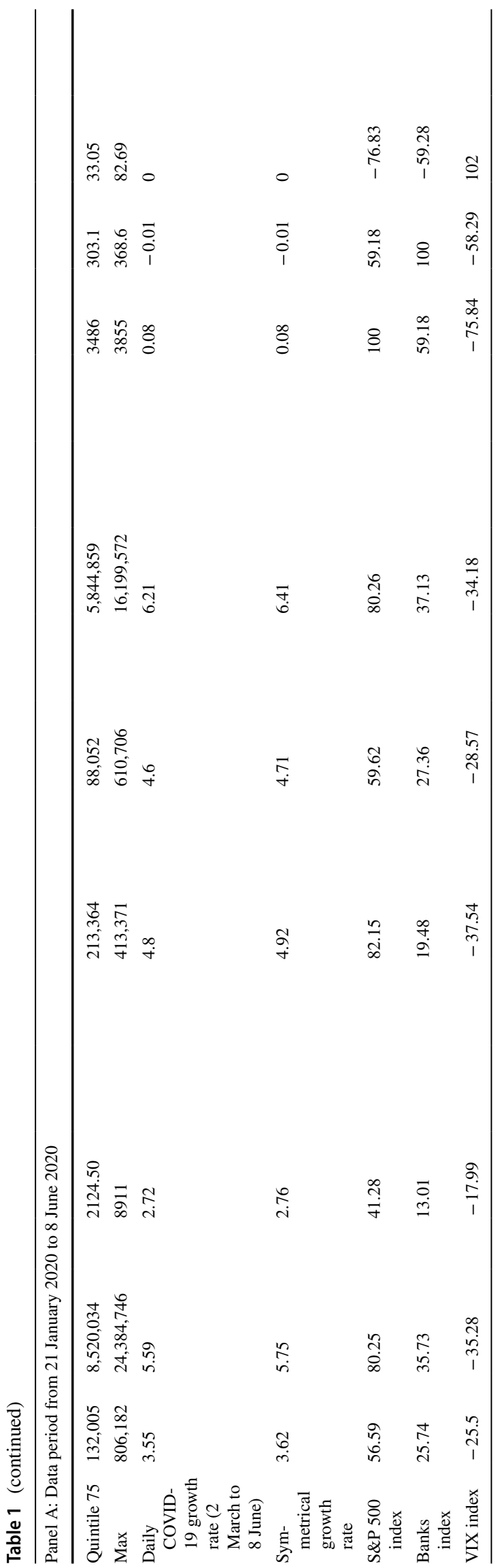

of individuals contracted with COVID-19 worldwide were unaware about the virus. This is evident where by 31 January 2021 , around $14.86 \%$ of the American population was expected to be infected with the virus. Furthermore, geometric data indicates that the number of COVID-19 patients is growing at a rate of $10.63 \%$ per day, which translates to $11.23 \%$ growth rate. Meanwhile, the COVID19 death rate is increasing at $15.12 \%$ daily, which is equivalent to $16.22 \%$ growth rate. The constant spike in COVID-19 daily cases and deaths therefore foreshadows a worrying status of the pandemics particularly circa 8 June 2020. If we extend the COVID-19 virus-affected sample period to a year, these growth rates drop considerably ( 31 January 2021). Furthermore, the S\&P 500 indexes and the CBOE VIX index are volatile for the data cycle from 21 January 2020 to 8 June 2020 and 232.79 and 60.81 are the deviation values (15.88). The Chicago Board Options Exchange VIX index reached 82.67 on 16 March 2020, which was the highest VIX level ever recorded by the CBOE with 1.81 points over the Chicago Board Options Exchange VIX (80.86) on 20 November 2008.

Figure 1 shows the COVID-19 viral data, S\&P 500 index, and Chicago Board Options Exchange VIX index that plot the pattern of the pandemic, essential occurrences, and stock market reaction between 21 January 2020 and 8 June 2020. It can be seen that the S\&P 500 index (shown by the dark blue solid line) and the Chicago Board Options Exchange VIX (shown by the solid green line) both form vertical lines along with major global and domestic events. The S\&P 500 and VIX indexes also move in opposite directions with a correlation coefficient of $-93.77 \%$ (see panel B in Table 1). It is also worth noting that the highest VIX level ever recorded by CBOE is on 16 March 2020.

\section{Results and discussion}

\section{Volatility index of COVID-19 and green finance}

Following the recommendation of previous related research (Chow et al. 2020), this paper (VIXJ) further excerpted an extremely high jumping constituent from the VIX component amidst the COVID-19 period by comparing the other index jumping tails (e.g., component) to the VIX index. The predicted VIXJ is negative due to the third instant in our sample. In addition, the VIXJ absolute value was used in the assessment of the VIX index.

\section{S\&P 500 index and banks index jump component}

This paper evaluated the S\&P 500 volatility index by adopting the measure used by past studies (Andersen et al. 1999). 
In this regard, the volatility of the S\&P 500 and banks indices were determined by multiplying the 78 intra-day 5 -min squared $\log$ returns from 9:30 a.m. to 4:00 p.m. with the close-to-open night returns spanning the normal green finance hours. The realized volatility was then divided into a variation continuous component (VCC) and component variation a jump (CV). As shown in Eq. (7), the element of variation continuous component $(\mathrm{CV})$ was calculated by the 2-h threshold variation. In addition, the daily volatility index of the S\&P 500 was also calculated. Table 1 shows the continuous variation of the volatility realized index (S\&P 500) component where panel B presents the performed continuous variation and volatility, continuous variation, and jump variance components of the S\&P 500 banks index. The sample in both panels took place between 21 January 2020 and 8 June 2020.

\section{Volatility jump summary statistics}

Table 2 contains the statistical results for the leaps estimated which comprise the VIX index springs as well as the volatility springs of the S\&P 500 and S\&P 500 banks. The summary jump tail component (VIXJ) is presented through the VIX index in column one. Since the VIXJ has a - sign, the statistics are based on its absolute value, whereas the daily jump change component of the S\&P 500 index (JV) is shown in column two while the daily jump variation component of the S\&P 500 banks index (JVB) is shown in column three. All estimates are provided as a foundation in columns two and three. The data sample was collected between 21 January 2020 and 8 June 2020.

The results indicate that the magnitude of VIXJ (column one) varies from 0.002 to 8.6 with a standard deviation of 1.3. This illustrates that VIXJ is a crucial component of VIX when VIX is exceptionally high. As VIXJ is negative due to its skewed signals, it posits that the VIX index dramatically understates the market risk-neutral volatility amidst the volatile market conditions. The S\&P 500 index and S\&P 500 banks index both have lower volatility measured in points as shown in columns two and three. For the S\&P 500 index, column 3 (14.239) exhibits higher realized volatility spikes than column 2 (13.329). Figure 2 contains a summary of volatile jumps for the VIX index springs, volatility springs made by S\&P 500, and volatility springs carried out by S\&P 500 banks.

\section{COVID-19 index}

We used Google search traffic statistics to acquire five emotion indices in Google's Trends database. It was achieved via multiple Google search variations and keywords including COVID-19 pandemic, market sensitivity index, lockdown, and banking index. The results demonstrate that the COVID19 lockdown in mid-March has resulted in the green finance of market changes that piqued the public's attention, which then switched to unemployment and government assistance programs through banking and government relief initiatives at the end of April 2020.

\section{Volatility spike and sentiment index relationship}

This section discusses the relationship between the VIX (VIXJ) jumps, realized volatility jumps (JV) in the S\&P 500 index, and the five Google search sentiment indexes. It was found that the volatility of the S\&P 500 banks index has risen while the eight variables have been normalized by removing the respective standard deviations and dividing it by their means. It was orthogonalized as there is a significant link between the five Google search mood indexes. This resulted in three unit variables (i.e., VIXJs, JVs, JBs) as well as five standardized and orthogonalized Google search sentiment indexes (i.e., COVID-19, marketeering, lockdown, banking, government relief). We then added numerous macroeconomic control parameters to regulate

Fig. 1 COVID-19 data analysis

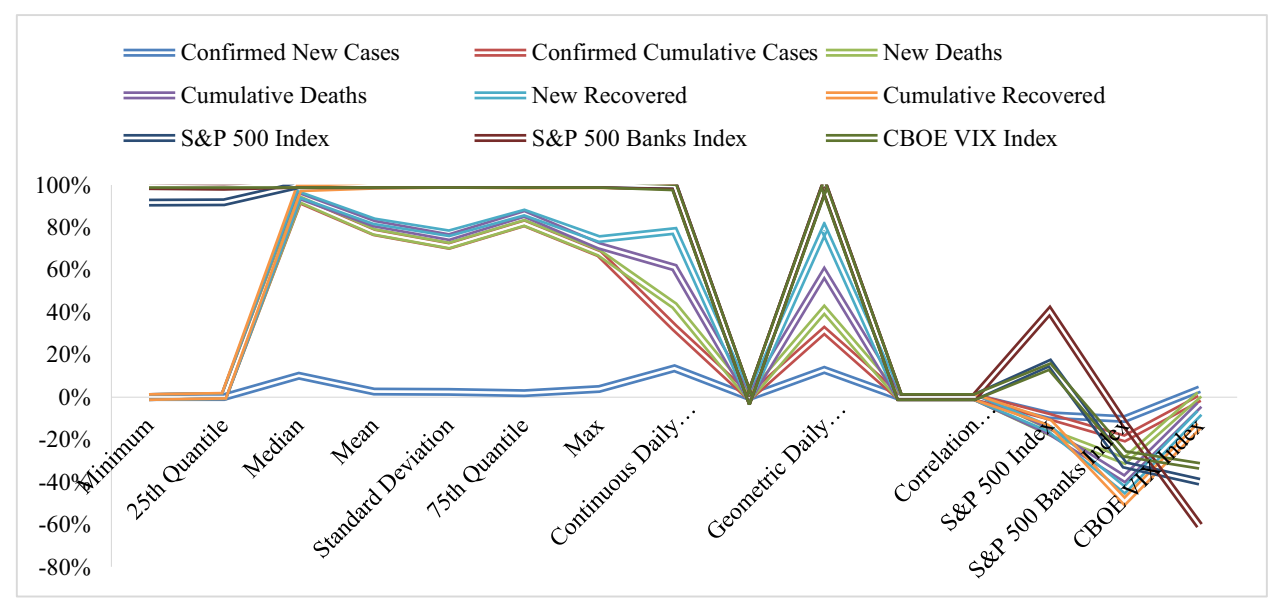


the macroeconomic conditions. The three macroeconomic control variables are the dividend yield logarithm (DY), loan dividend differential (CS), and the loan differential (TS) between the 10-year and 3-month trust yields. Table 3 shows the Pearson correlation coefficients between the eight variables and the three control variables, which comprise the correlation matrix for the standardized VIX index jumps (VIXJs), S\&P 500 realized volatility jumps, and S\&P 500 banks index realized volatility jumps. Meanwhile, results show the five orthogonalized Google search indexes. All variables were normalized by deleting the mean values and dividing the standard deviations to eliminate the magnitude effect. All data were collected between 21 January 2020 and 8 June 2020 and the results are presented in descriptive statistics and percentages.

The results in Table 3 show that the five components of the Google search sentiment index are unrelated. Such finding is not surprising considering that all the search factors were orthogonalized and unconnected. The standardized VIX jump corresponds to the volatility jump index of S\&P 500 index as well as the S\&P 500 banks index with the correlation coefficients of $45.27 \%$ and $43.46 \%$, respectively. Moreover, the volatility jump indexes of both S\&P 500 and S\&P 500 banks are closely linked with a

Table 2 The fluctuations in the VIX index (S\&P 500)

\begin{tabular}{llll}
\hline & $-($ One $)$ & -(Two) & -(Three) \\
\hline & VIXJ & JV & JVB \\
Min value & 5.848 & 1 & 1 \\
Quantile 25 & 7.801 & 9.248 & 9.481 \\
Median value & 1.382 & 0.792 & 3.147 \\
Mean value & 1.536 & 5.008 & 14.239 \\
S. Deviation & 6.0 & 29.080 & 21.958 \\
Quantile 75 & 5.995 & 0.760 & 92.916 \\
Max value & 7.4 & 73.905 & 156.871 \\
\hline
\end{tabular}

92.51\% correlation coefficient. The three jump variables also show low correlation coefficients with the exception for JVs and JVBs. This is expected given that banks are part of the global economy. Such results demonstrate that the three jumping volatility factors are distinct and agree with the "Data on COVID-19 pandemic" section of our theoretical projection. Moreover, the Google search sensitivity index of government relief has a negative correlation with the volatility jump indexes of S\&P 500 banks $(-24.03 \%)$ and S\&P $500(-21.79 \%)$. As shown in Fig. 3, the correlations between the three and eight key variables are substantially low. The association between volatility jumps and the current Google search sentiment indexes was then investigated using regression analysis. Figure 3 shows that the regression specifications (1) for four Google search sentiment index variables, namely COVID-19, Market, Lockdowns, and Banking, are statistically significant with the Newey-West (1987) $t$-statistic hetero-scedasticity and corrected autocorrelation (HAC) of 3.37, 5.65, 3.03, and 1.71, respectively. However, such significance is not demonstrated by government relief. In contrast, only the HAC $t$-statistics of 2.44, 3.62, and 3.16 are statistically significant with NWIs in the regression specification (2).

Figure 3 shows the association between the five orthogonalized Google search indices and the VIX index. The VIX index experienced a rise in volatility in relation to the $\mathrm{S} \& \mathrm{P}$ 500 index and the S\&P 500 banks index. Table 4 comprises three macroeconomic control variables and search indices ((1) COVID-19, (2) market, (3) lockdowns, (4) banking, and (5) government relief). The dividend yield logarithm, C.S. (the difference between Moody's BAA and AAA bond yield indices) and T.S. (the disparity between Moody's BAA and AAA bond yields), is one of the three macroeconomic control variable indexes (the term spread the difference between the 10-year and the 3-month treasury yields). Annualized percentages were used for all variables while the Google search indexes were used in column 1. Meanwhile, column

Fig. 2 Volatility jump summary

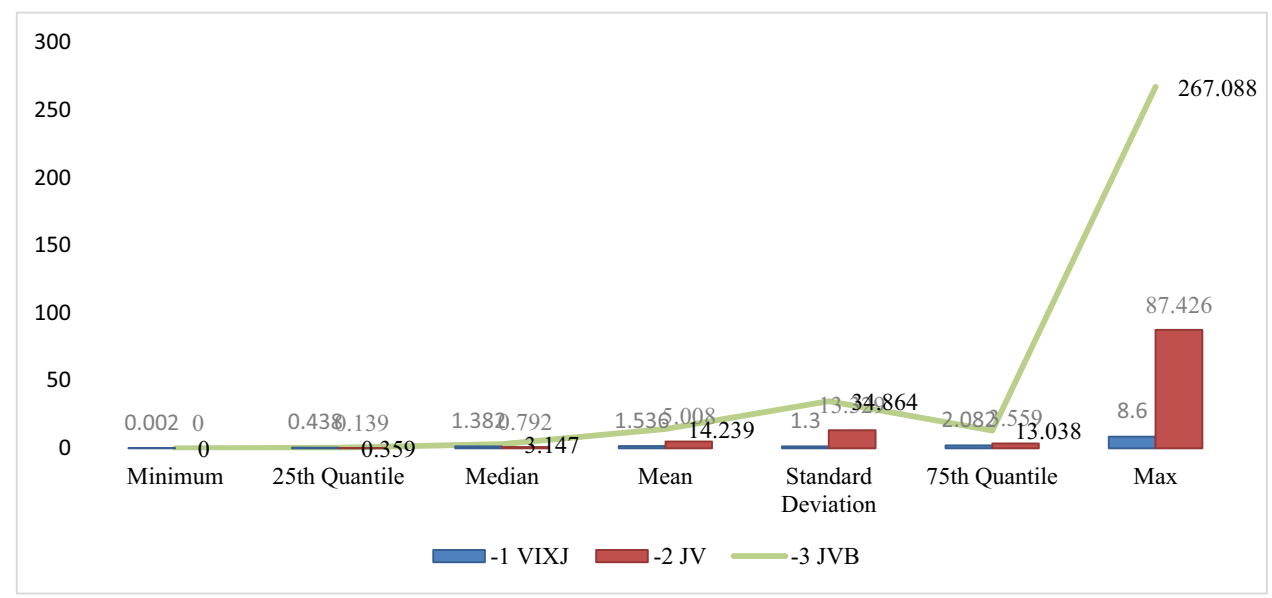


Table 3 Correlation matrix of volatility jumps and Google search sentiment indices

\begin{tabular}{|c|c|c|c|c|c|c|c|c|c|c|c|}
\hline & VIXJ & JV & JVB & COVID-19 & Market & Lockdown & Banking & Govt. relief & $\log (\mathrm{DY})$ & $\mathrm{CS}$ & $\mathrm{TS}$ \\
\hline VIXJ & - & & & & & & & & & & \\
\hline JV & 45.27 & - & & & & & & & & & \\
\hline JVB & 43.46 & 92.51 & - & & & & & & & & \\
\hline COVID-19 & 42.79 & 20.71 & 13.25 & - & & & & & & & \\
\hline Market & 54.98 & 61.51 & 57.15 & 0 & - & & & & & & \\
\hline Lockdown & 42.11 & 10.65 & 11.99 & 0 & 0 & - & & & & & \\
\hline Banking & 12.75 & 1.11 & 8.27 & 0 & 0 & 0 & - & & & & \\
\hline Relief by government & 8.62 & -375.3 & -75.79 & 0 & 0 & 0 & 0 & - & & & \\
\hline $\log (\mathrm{DY})$ & -7.08 & 3.92 & 7.91 & -53.49 & 92.60 & -0.21 & -67.82 & -79.41 & - & & \\
\hline $\mathrm{CS}$ & 52.56 & 5.87 & 11.01 & 41.49 & 10.42 & 15.54 & 39.77 & 55.19 & -43.82 & - & \\
\hline TS & 60.26 & 14.31 & 14.47 & 51.13 & 21.33 & 43.96 & -4.4 & & & & \\
\hline
\end{tabular}

2 used the Google search indexes to explain the jumps in the VIX index and column 3 used Google search indexes to explain the increase in the S\&P 500 index realized volatility jumps (JV) during COVID-19 4. The market lockdowns, banking, and govt. relief explain the increases in the $\mathrm{S}$ and $\mathrm{P}$ 500 banks index realized volatility increases (JVBs). All variables have been normalized by subtracting the mean values and dividing it with the standard deviation. The regression $t$-statistics are presented in brackets (round bracket) while the Newey-West (1987) $t$-statistics are provided in parenthesis (square bracket).

Data for the adjusted coefficient of determination $\left(R^{2}\right)$ was collected from 21 January 2020 through 8 June 2020. It was found that the jump components of the VIX in the COVID-19 index, market index, lockdown index, and banking index have been increasing, thus serving as the evidence points to hypothesis 1 . During the COVID-19 period, the green market and green financing lockdowns were largely negative where the volatility increase in the options market, where the deal was advanced, was largely due to these factors. The engagement of banks and central banks appears to have resulted in an increase in optional market volatility. Moreover, the volatility of the jump components has finally been realized in the S\&P 500 index and the S\&P 500 banks index. Both the COVID-19 index and market index also prompted increased volatility as evident by the S\&P 500 jump component index and the S\&P 500 banks index. As a result of the increased public knowledge and alarm, the COVID-19 index and market index values also increased, thus contributing to volatility. On the other hand, the green finance of government aid efforts has been reassuring where government relief measures are typically aimed at families, individuals, and small companies with relatively limited income. Jump volatility has also dropped considerably in the government relief effort index. Such findings thus confirm our prediction in the "Hypothesis 2" section.

\section{Banking green finance and lockdown information learning}

This paper further examined if conduct traders are learning from the price movements. Our data in Table 4 reveal that
Fig. 3 Correlations of all indicator indexes

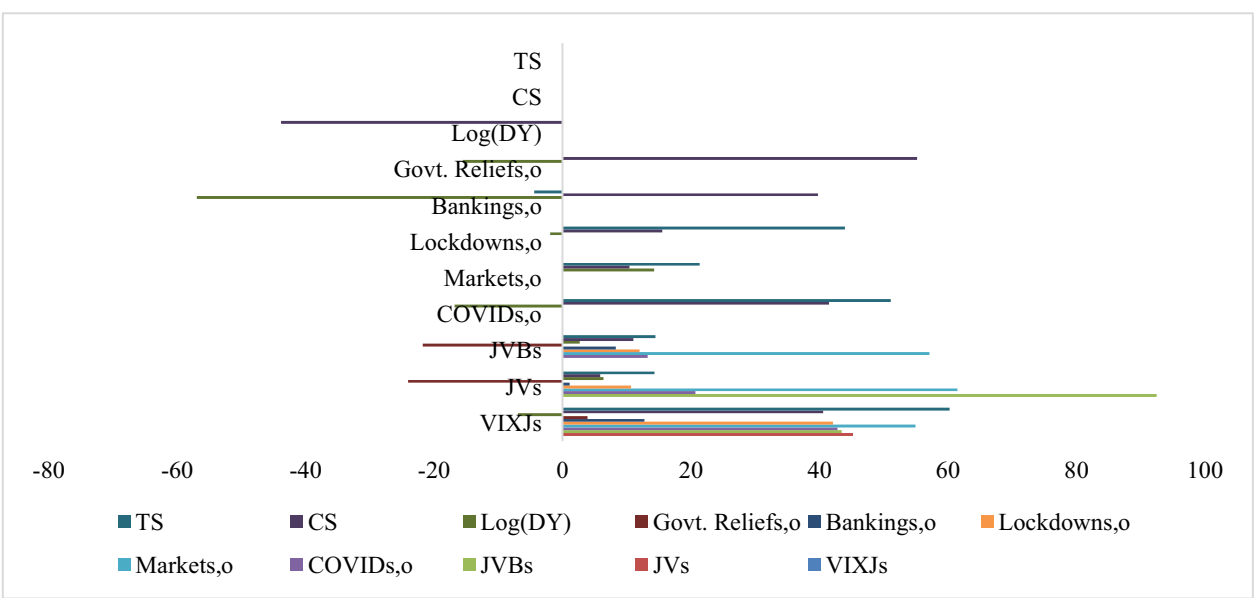


while the banking group sentiment index causes an increment in stock, traders are unaware of the VIX (optional) index. One apparent question is whether behavioral traders eventually learn about it and adjust their trade strategies accordingly. We also investigated if the lagged bank sentiment index values have a significant impact on stock market jump volatility in order to answer the issue. This was achieved by looking at the lags from day 1 until day 5. As shown in Table 5, it was found that the 5-day bank index has significant explanatory power for minimizing the jump's volatility, including in the aspects of VIX index (VIXJs), the S\&P 500 index realized volatility jumps (JVs), S\&P 500 banks index realized volatility jumps (JVBs), the contemporary orthogonalized Google search indices of COVID-19, market, lockdowns, banking, and government relief, and the orthogonalized lagged Google search banking index (banking). Meanwhile, the three macroeconomic control variables are the logarithm of the dividend yield (CS), the difference between Moody's BAA

Table 4 Sentiment indices on volatility jumps S\&P 500 index and S\&P 500 banks index

\begin{tabular}{|c|c|c|c|}
\hline & -1 & -2 & -3 \\
\hline & VIXJ $^{\mathrm{s}}$ & $\mathrm{JV}^{\mathrm{s}}$ & $\mathrm{JVB}^{\mathrm{s}}$ \\
\hline COVID-19 & 0.90 & 0.75 & 0.69 \\
\hline$t$-statistic & $(0.30 * * *)$ & $(3.87 *)$ & -0.45 \\
\hline Newey-West $t$-statistic & {$[4.19 * * *]$} & {$[9.32 * *]$} & {$[0.98]$} \\
\hline Market & 0.47 & 0.66 & 0.58 \\
\hline$t$-statistic & $(7.11 * * *)$ & $(7.78 * * *)$ & $(6.43 * * *)$ \\
\hline Newey-West $t$-statistic & {$[9.22 * * *]$} & {$[9.03 * * *]$} & {$[6.75 * * *]$} \\
\hline Lockdown & 5.14 & 0.58 & 0.56 \\
\hline$t$-statistic & $(0.769 * * *)$ & -0.20 & -4.86 \\
\hline Newey-West $t$-statistic & {$\left[9.65^{* * *}\right]$} & {$[9.67]$} & {$[0.50]$} \\
\hline Banking $t-5$ & 6.92 & -0.53 & -0.12 \\
\hline$t$-statistic & $(4.91 * *)$ & $(-0.62)$ & $(-0.34)$ \\
\hline Newey-West $t$-statistic & {$[1.71 *]$} & {$[-0.95]$} & {$[-0.29]$} \\
\hline Relief by government & -0.12 & -0.23 & -0.33 \\
\hline$t$-statistic & $(-1.36)$ & $(-1.98 * *)$ & $(-2.62 * * *)$ \\
\hline Newey-West $t$-statistic & {$[-0.99]$} & {$\left[-3.16^{* * *}\right]$} & {$[-4.47 * * *]$} \\
\hline $\log (\mathrm{DY})$ & 0.56 & -0.34 & -0.11 \\
\hline$t$-statistic & -0.85 & $(-0.40)$ & $(-0.12)$ \\
\hline Newey-West $t$-statistic & {$[0.67]$} & {$[-0.68]$} & {$[-0.19]$} \\
\hline CS & 0.07 & 0.44 & 0.89 \\
\hline$t$-statistic & -0.19 & -0.97 & 0.91 \\
\hline Newey-West $t$-statistic & {$[0.20]$} & {$[1.03]$} & {$[4.78]$} \\
\hline TS & 1.02 & -0.57 & -0.5 \\
\hline$t$-statistic & $(2.34 * *)$ & $(-1.02)$ & $(-0.7)$ \\
\hline Newey-West $t$-statistic & {$[2.02 * *]$} & {$[-0.69]$} & {$[-0.91]$} \\
\hline Adj. $R^{2}$ & $67.38 \%$ & $46.22 \%$ & $39.25 \%$ \\
\hline
\end{tabular}

$* * *$ means $1 \%$ significance level, $* *$ means $5 \%$ significance level, and * means $10 \%$ significance level. and AAA bond yield indices, and TS (the spread between Moody's BAA and AAA bond yield indices) with the term spread difference between the 10-year and the 3-month treasury yields. The percentages for all variables have been adjusted to be annualized. Furthermore, column 1 used the Google search indexes to explain the spikes in the VIX index while similar method was used in columns 2 and 3 to explain the jumps in the S\&P 500 index realized volatility jumps (JVs) and the S\&P 500 banks index realized volatility jumps (JVBs). All variables were normalized by subtracting the mean values before dividing it with the standard deviations. The regression $t$-statistics are presented in brackets (round bracket), whereas the NeweyWest (1987) $t$-statistics are shown in parenthesis (square bracket). Table 5 shows the bank lagged index.

The adjusted coefficient of determination is abbreviated as $R^{2}$. From January 21, 2020 through January 8, 2021, the J.V. components of the 5-day lagged bank index jumped. Table 5 and columns 2 and 3 show significant reductions (S\&P 500 index increases) and JVB (S\&P 500). By - 2, 79, and $-3,09$, respectively, Newey (1987)-West's HAC $t$-statistic, hypothesis 3 shows that the coefficient has a negative sign where successful monetary policy initiatives could provide significant green finance to the economy. On the other hand, it is difficult to translate banking data into asset price significance due to its complexity. Before establishing successful and balanced green finance systems, behavioral traders may need to learn from price dynamics. As expected, the delay in bank contribution to the jump component was a negative indicator of realized volatility in the S\&P 500 index and the S\&P 500 banks index. As shown by the data in Table 6, the banking green finance exam is identical to the lockdown green finance exam, which is evident by the VIX index realized volatility jumps in the S\&P 500 index, realized volatility jumps in the S\&P 500 banks index (JVBs), and the most recent orthogonalized Google search indices (i.e., COVID-19, markets, banking, government relief). The data also includes the orthogonalized lagged Google search banking index (lockdown $t-5$ ) and the dividend yield logarithm, CS, and annualized percentages were used for all variables. Meanwhile, columns 1 and 2 utilized Google search indices (COVID-19, markets, lockdown $t-5$, banking, government relief) to explain the VIX index (VIXJs) jumps while column 3 used Google search indices (COVID19 , markets, lockdown $t-5$, banking, govt. relief) to explain the S\&P 500 leaps (JVBs). All variables were normalized by removing the means and dividing the standard deviations. The regression $t$-statistics are presented in parentheses (round bracket) while the Newey-West (1987) $t$-statistics are presented in square bracket.

The corrected coefficient of determination is denoted by $R^{2}$ where the data was collected from 21 January 2020 to 8 June 2020. The JVs leap component is the 5-day lagged 
Table 5 Bank lagged index on VIX and S\&P 500 volatility jumps

\begin{tabular}{|c|c|c|c|}
\hline & $-($ One $)$ & $-($ Two $)$ & -(Three) \\
\hline & VIXJ & JV & JVB \\
\hline COVID-19 & 0.56 & 0.81 & 0.70 \\
\hline$t$-statistic & $(0.041 * * *)$ & $(5.19 * *)$ & -0.19 \\
\hline Newey-West $t$-statistic & {$[0.32 * * *]$} & {$[1.71 * *]$} & {$[0.95]$} \\
\hline Market & 0.32 & 0.2 & 0.25 \\
\hline$t$-statistic & $(0.54 * * *)$ & $(2.81 * * *)$ & $(5.73 * * *)$ \\
\hline Newey-West $t$-statistic & {$\left[0.45^{* * *}\right]$} & {$[8.91 * * *]$} & {$[6.34 * * *]$} \\
\hline Lockdown & 0.92 & 0.95 & 0.98 \\
\hline$t$-statistic & $(9.67 * * *)$ & $(3.42 * *)$ & -9.41 \\
\hline Newey-West $t$-statistic & {$\left[89.45^{* * *}\right]$} & {$[6.31]$} & {$[0.23]$} \\
\hline Banking $t-5$ & 0.4 & -0.75 & -0.43 \\
\hline$t$-statistic & -2.78 & $(-8.91)$ & $(-0.65)$ \\
\hline Newey-West $t$-statistic & {$[5.65]$} & {$[-9.61 * * *]$} & {$[-8.94 * * *]$} \\
\hline Relief by government & 0.23 & -0.65 & -0.65 \\
\hline$t$-statistic & -0.45 & $\left(-2.75^{*}\right)$ & $(-7.75)$ \\
\hline Newey-West $t$-statistic & [0.89] & {$[-8.43 * *]$} & {$[-8.93 * * *]$} \\
\hline $\log (\mathrm{DY})$ & -0.27 & -0.45 & -0.82 \\
\hline$t$-statistic & $(-0.91)$ & $(-0.65)$ & $(-0.65)$ \\
\hline Newey-West $t$-statistic & {$[-0.34]$} & {$[-0.10]$} & {$[-8.23]$} \\
\hline CS & -0.22 & 0.43 & 8.91 \\
\hline$t$-statistic & $(-0.35)$ & -9.54 & $\left(4.61^{* *}\right)$ \\
\hline Newey-West $t$-statistic & {$[-0.74]$} & {$[6.84]$} & {$[0.09 *]$} \\
\hline TS & 0.31 & -0.65 & -0.65 \\
\hline$t$-statistic & -4.10 & $(-9.54 *)$ & $(-9.52)$ \\
\hline Newey-West $t$-statistic & {$\left[6.65^{*}\right]$} & {$[-0.71]$} & {$[-0.54]$} \\
\hline Adj. $R^{2}$ & $87.23 \%$ & $12.75 \%$ & $91.78 \%$ \\
\hline
\end{tabular}

$* * *$ means $1 \%$ significance, $* *$ means $5 \%$ significance, and $*$ means $10 \%$ significance.

lockdown index in regressions (2) and (3) in Table 6. According to our findings in Table 4, the S\&P lockdown index revealed that the VIX index's jump component dramatically increased but had no effect on the jumping stock market volatility. This demonstrates that astute investors recognize the negative economic and market-price ramifications of lockdowns. On the other hand, commodity traders understand volatility patterns over time. The results show that the impact of stock market volatility rises in the reduce lockdown index.

\section{Conclusion and policy implication}

The COVID-19 pandemic has prompted a widespread alarm among market participants and financial market volatility. Although the importance of green finance has been long highlighted, its importance and need have once again been justified by the post COVID-19 outcomes. This paper investigated the effect of COVID-19 information and consequent
Table 6 Lagged lockdown index and statistic results

\begin{tabular}{|c|c|c|c|}
\hline & $-(1)$ & $-(2)$ & $-(3)$ \\
\hline & VIXJ & JV & Job \\
\hline COVID-19 pandemic & 0.38 & 0.35 & 0.18 \\
\hline$t$-statistic & $4.02 * * *$ & $3.02 * * *$ & -1.4 \\
\hline$t$-statistic (Newey-West) & $5.15 * * *$ & $2.63 * * *$ & 0.98 \\
\hline Market & 0.47 & 0.66 & 0.58 \\
\hline$t$-statistic & $6.43 * * *$ & $7.43^{* * *}$ & $4.99 * * *$ \\
\hline$t$-statistic (Newey-West) & $5.41 * * *$ & $4.66 * * *$ & $2.27 * * *$ \\
\hline Lockdown $t-5$ & 0.03 & -0.19 & -0.22 \\
\hline$t$-statistic & -0.22 & -2.55 & $-2.81 *$ \\
\hline$t$-statistic (Newey-West) & 0.22 & $-2.76^{*}$ & $-1.81 * * *$ \\
\hline Bank index & 0.3 & -0.07 & 0 \\
\hline$t$-statistic & $1.33^{* *}$ & -0.49 & -0.02 \\
\hline$t$-statistic (Newey-West) & 2.60 & -2.02 & 0.01 \\
\hline Relief by government & -0.08 & -0.17 & -0.30 \\
\hline$t$-statistic & -0.81 & -2.41 & $-2.88 *$ \\
\hline NW $t$-statistic & -0.65 & $-1.66^{* * *}$ & $-3.77 * * *$ \\
\hline $\log (\mathrm{DY})$ & 0.46 & -0.01 & 0.13 \\
\hline$t$-statistic & -0.63 & $(-0.01)$ & -0.13 \\
\hline$t$-statistic (Newey-West) & 0.51 & {$[-0.02]$} & 0.21 \\
\hline $\mathrm{CS}$ & -0.26 & 0.34 & 0.56 \\
\hline$t$-statistic & -0.71 & -0.74 & -1.15 \\
\hline$t$-statistic (Newey-West) & -0.70 & 0.88 & 1.77 \\
\hline TS & 1.29 & -0.49 & -0.03 \\
\hline$t$-statistic & $2.69 * *$ & -0.84 & -0.05 \\
\hline$t$-statistic (Newey-West) & $1.99 * *$ & -0.66 & -0.04 \\
\hline Adj. $R^{2}$ & $71.35 \%$ & $42.61 \%$ & $41.39 \%$ \\
\hline
\end{tabular}

Note: $* * *$ means $1 \%$ significance, $* * 5 \%$ significance, and $* 10 \%$ significance.

feeling fluctuations on volatility jumps in stock and options markets. Five sentimental indices for Google search were identified, namely (1) COVID-19 Sentiment Index, (2) Sensitivity Market Index, (4) Lockdown Index Sentiment, (5) Bank Sentiment Index, and (6) Government Aid Sentiment Index. The impact of several perception indicators on the volatility jumps of both stock and options market was determined through a theoretical model of behavioral and sophisticated traders' green finance strategies. The leap tail component of the CBOE VIX index, the jump component of the S\&P 500's volatility realized index, and the volatility realized in the S\&P 500 banks index were all analyzed. It was found that the jump component in the VIX index had skyrocketed in response to the COVID-19 index, market index, lockdown index, and banking index. On the other hand, the S\&P 500 index and S\&P 500 banks index showed that volatility increased the leap component, although the COVID-19 result was weaker for the S\&P 500 banks index. Furthermore, the state relief effort index reduced the jump volatility of the S\&P 500 and S\&P 500 banking indexes. The 
S\&P $500 \mathrm{~S}$ and P 500 banks index and the S\&P $500 \mathrm{~S}$ and P 500 index were delayed for 5 days. Our evidence thus indicates that equities traders learn about the value of banking and lockout information with 5 days delay. One may argue that they can redistribute the undue weight on COVID-19 green finance with some experiential learning for banks and lockout green finance. These findings correspond to what our model predicts and gives light on how diverse COVID19 information is communicated into the price in light of the dynamics of advanced options green finance and possibly more sentiment-based stock green finance. However, it raises the question on what accounts for the significant shifts in market sentiment and the resulting volatility in the face of unprecedented market volatility. Our findings also add to the understanding of the link between investor sensitivity and market volatility. Additional research can expand the scope of this study by including a worldwide framework that examines the impact of market volatility on investor sentiment in other countries.

Author contribution Luc Phan Tan: writing-original draft. Muhammad Sadiq: writing - review and editing. Talla M Aldeehani: conceptualization, data curation. Syed Ehsan Ullah: methodology. Puteri Mutira: visualization. Hieu Vu Minh: editing, data curation, supervision.

Data availability The data that support the findings of this study are attached.

\section{Declarations}

Ethics approval and consent to participate We declare that we have no human participants, human data, or human tissues.

Consent for publication Not applicable.

Competing interests The authors declare no competing interests.

\section{References}

Chien F, Sadiq M, Kamran HW, Nawaz MA, Hussain MS, \& Raza M (2021) Co-movement of energy prices and stock market return: Environmental wavelet nexus of COVID-19 pandemic from the USA, Europe, and China. Environ Sci Pollut Res. https://doi.org/ 10.1007/s11356-021-12938-2

Andersen TG, Bollerslev T, Lange S (1999) Forecasting financial market volatility: sample frequency vis-a-vis forecast horizon. J Empir Financ 6(5):457-477

Arif M, Hasan M, Alawi SM, Naeem MA (2021) COVID-19 and time-frequency connectedness between green and conventional financial markets. Glob Financ J. https://doi.org/10.1016/j.gfj. 2021.100650

Baker SR, Bloom N, Davis SJ, Kost K, Sammon M, Viratyosin T (2020) The unprecedented stock market reaction to COVID-19. Rev Asset Pricing Stud 10:742-758
Basu A (2020) Estimating the infection fatality rate among symptomatic COVID-19 cases in the United States: study estimates the COVID-19 infection fatality rate at the US county level. Health Aff 39:1229-1236

Beraha I, Đuričin S (2020) The impact of COVID-19 crisis on mediumsized enterprises in Serbia. Econ Anal 53:14-27

Bretscher L, Hsu A, Simasek P, Tamoni A (2020) COVID-19 and the cross-section of equity returns: impact and transmission. Rev Asset Pricing Stud 10:705-741

Cheng J (2020) How to build a stablecoin: certainty, finality, and stability through commercial law principles. Berkeley Bus LJ 17:320

Chow KV, Jiang W, Li B, Li J (2020) Decomposing the VIX: implications for the predictability of stock returns. Financ Rev 55:645-668

Chuan JN, Mahdi S, Kenneth R (2021) The impact of Covid-19 pandemic on stock market return volatility: evidence from Malaysia and Singapore. Asian Econ Financ Rev 11:191-204

Da Z, Engelberg J, Gao P (2011) In search of attention. J Finance 66:1461-1499

Du J, Kapadia N (2012) The tail in the volatility index. U. Massachusetts, Amherst Work. Pap

Ferreira CM, Sá MJ, Martins JG, Serpa S (2020) The COVID-19 contagion-pandemic dyad: a view from social sciences. Societies 10:77

Guo Y, Li P, Li A (2021) Tail risk contagion between international financial markets during COVID-19 pandemic. Int Rev Financ. Anal 73:101649

Hanke M, Kosolapova M, Weissensteiner A (2020) COVID-19 and market expectations: evidence from option-implied densities. Econ. Lett 195:109441

Jackwerth J (2020) What do index options teach us about COVID-19? Rev Asset Pricing Stud 10:618-634

Lemmon M, Ni SX (2014) Differences in trading and pricing between stock and index options. Manage Sci 60:1985-2001

Li L, Strahan PE, Zhang S (2020) Banks as lenders of first resort: evidence from the COVID-19 crisis. Rev Corp Financ Stud 9:472-500

Li W, Chien F, Kamran H, W, Aldeehani TM, Sadiq M, Nguyen VC, \& Taghizadeh-Hesary F (2021): The nexus between COVID-19 fear and stock market volatility, Econ Res-Ekon Istraž. https://doi.org/ 10.1080/1331677X.2021.1914125

Piñeiro-Chousa J, López-Cabarcos MÁ, Caby J, Šević A (2021) The influence of investor sentiment on the green bond market. Technol Forecast. Soc. Change 162:120351

Sadiq M, Hsu CC, Zhang Y, Chien FS (2021a) COVID-19 fear and volatility index movements: empirical insights from ASEAN stock markets. Environ Sci Pollut Res. https://doi.org/10.1007/ s11356-021-15064-1

Sadiq M, Nonthapot S, Mohamad Keong OC, Ehsanullah S, Iqbal N (2021b) Does Green Finance Matters for Sustainable Entrepreneurship and Environmental Corporate Social Responsibility during Covid-19?, China Finance Rev Int. https://doi.org/10.1108/ CFRI-02-2021-0038

Štreimikiene D, Kaftan V (2021) Green finance and the economic threats during COVID-19 pandemic. Terra Econ 19:105-113

Yang C-C, Chuang H-Y (2020) The strategy for return to work after the COVID-19 pandemic on small and medium-sized enterprises. J Occup Environ Med 62:e471-e472

Yoshino N, Taghizadeh-Hesary F, Otsuka M (2021) Covid-19 and optimal portfolio selection for investment in sustainable development goals. Financ. Res. Lett 38:101695

Zhang J-B, Gao Y-C, Cai S-M (2020) The hierarchical structure of stock market in times of global financial crisis. Phys. A Stat. Mech. its Appl. 542:123452

Publisher's note Springer Nature remains neutral with regard to jurisdictional claims in published maps and institutional affiliations. 